\title{
High-flow nasal cannula therapy: can it be recommended as initial or rescue care for infants with moderate bronchiolitis in the paediatric ward?
}

\author{
Amir Kugelman \\ Affiliation: Dept of Neonatology and Pediatric Pulmonary Unit, Rambam Medical Center, Rappaport Faculty of \\ Medicine, Technion, Haifa, Israel.
}

Correspondence: Amir Kugelman, Rambam Medical Center, Neonatology, 24 Tel Mane Street, Haifa, 3436414, Israel. E-mail: amirkuglagmail.com

@ERSpublications

The current literature does not support routine or initial use of HFNC in infants with moderate bronchiolitis - unless criteria for use are more selective. Rescue HFNC might be justified if the threshold for standard care failure is better delineated. https://bit.ly/3a $90 \mathrm{EXb}$

Cite this article as: Kugelman A. High-flow nasal cannula therapy: can it be recommended as initial or rescue care for infants with moderate bronchiolitis in the paediatric ward? Eur Respir J 2020; 56: 2001020 [https://doi.org/10.1183/13993003.01020-2020].

The American Academy of Pediatrics (AAP) guidelines recommend only supportive therapy for hospitalised infants with viral bronchiolitis. This includes oxygen therapy for hypoxaemia, respiratory support and the maintenance of hydration [1]. High-flow nasal cannula (HFNC) therapy has gained increasing popularity when there is a need for noninvasive respiratory support in infants with bronchiolitis, thanks to ease of use, perceived patient comfort and reduced nasal trauma. However, despite its widespread implementation, the clinical advantages of HFNC when compared to standard care (e.g. low-flow oxygen therapy) have not been proven by the current literature to justify its routine practice or initial treatment for infants with moderate bronchiolitis outside the paediatric intensive care unit (PICU) [2,3].

HFNC results in washout of anatomical and physiological dead space, improves fractions of alveolar gases, decreases airway resistance and work of breathing, and creates a level of positive end expiratory pressure that may contribute to its beneficial effect [4]. In infants aged $<12$ months with bronchiolitis, HFNC oxygen/air delivered at $8 \mathrm{~L} \cdot \mathrm{min}^{-1}$ compared with $2 \mathrm{~L} \cdot \mathrm{min}^{-1}$ resulted in increased end-expiratory lung volume and improved respiratory rate, inspiratory oxygen fraction and $\mathrm{FiO}_{2}$, and peripheral oxygen saturation $\left(S_{\mathrm{pO}_{2}}\right)$ [5]. Another physiological study demonstrated that a flow rate equal to or above $2 \mathrm{~L} \cdot \mathrm{kg}^{-1} \cdot \mathrm{min}^{-1}$ generated a clinically relevant pharyngeal pressure, with improved breathing pattern and rapid unloading of respiratory muscles, in young infants $<6$ months of age with acute respiratory syncytial virus bronchiolitis [6].

Two recent systematic reviews investigated the effects of HFNC versus other forms of oxygen therapy for bronchiolitis $[2,3]$. The reviews found no differences in length of stay, length of oxygen supplementation, transfer rates to PICU, intubation rates, length of stay in PICU, respiratory rate, heart rate or adverse events. A significant reduction of the incidence of treatment failure was observed in the HFNC group compared with standard therapy, but there was a significant increase of the incidence of treatment failure in HFNC group compared with nasal continuous positive airway pressure (NCPAP) group [2, 3]. 
To date there have been only two large randomised controlled trials (RCTs) published comparing HFNC and standard care in infants with moderate bronchiolitis admitted to the paediatric ward with equivocal results [7, 8]. In the current issue of the European Respiratory Journal, DuRAND et al. [9] report a randomised controlled multicentre study of HFNC in infants with moderate bronchiolitis in the target population of infants $<6$ months of age. This study may help to generalise the results of the previous studies [7, 8], despite different definitions of primary outcomes, inclusion criteria (age groups and definition of moderate bronchiolitis), treatment routines (level of target oxygen saturation, management of flow while delivering HFNC) and criteria for treatment failure (table 1).

The benefits of the HFNC were judged according to short- and long-term outcomes compared to standard care. Short-term outcomes included clinical severity score or deterioration, proportion of 'treatment failure' requiring escalation of care, comfort, feeding and adverse events. Long-term outcomes looked at the need to be admitted to PICU, need for endotracheal ventilation, the duration of oxygen supplementation and length of stay in hospital or in the PICU. Beyond the clinical implications, the latter measures are translated into cost and emotional stress; Thus, cost-effectiveness should be taken into consideration. Expenses could result from consumables needed for HFNC, but savings could relate to the possibility of avoiding intensive care in the PICU [8].

The outcomes of the three studies comparing HFNC versus standard care in infants with bronchiolitis in the pediatric ward are summarised in table 1. The data shows that while HFNC may have short-term benefits (mainly in relief of respiratory distress and work of breathing, and maybe treatment failure that could be rescued by HFNC), it does not appear to result in any significant long-term advantage. Accordingly, routine initial use does not seem to be justified.

However, HFNC might have a role as a rescue therapy. In two of the studies HFNC was beneficial in stabilising the infants by reducing escalation of care [7, 8], and in the third study, not allowing crossover and rescue with HFNC, there was no statistical difference in escalation of care to nasal respiratory support [9]. It is worth noting that the majority of infants ( 68 to $80 \%$ in the three studies [7-9]) in the standard care groups were successfully treated without escalation of care [10]. Yet, in the two studies allowing the infants rescue with HFNC, it was beneficial in $\sim 60 \%$ of the infants who failed the standard care $[7,8]$.

TABLE 1 Design and main outcomes of the largest three randomised controlled trials (RCTs) comparing high-flow nasal cannula (HFNC) therapy versus standard care for infants with moderate bronchiolitis on the paediatric ward

\begin{tabular}{|c|c|c|c|}
\hline \multirow[t]{3}{*}{ Design } & Multicentre RCT & Single-centre RCT & Multicentre RCT \\
\hline & $\begin{array}{l}\text { Age }<12 \text { months } \\
n=1472(739 / 733)\end{array}$ & $\begin{array}{l}\text { Age }<24 \text { months } \\
n=202(101 / 101)\end{array}$ & $\begin{array}{l}\text { Age }<6 \text { months } \\
n=268(133 / 135)\end{array}$ \\
\hline & $S_{\mathrm{pO}_{2}}$ goal $\geqslant 92 \%$ or $\geqslant 94 \%$ & $\mathrm{~S}_{\mathrm{pO}_{2}}$ goal $\geqslant 94 \%$ & $\mathrm{~S}_{\mathrm{pO}_{2}}$ goal $\geqslant 94 \%$ \\
\hline Intervention & $\begin{array}{l}\text { HFNC } 2 \mathrm{~L} \cdot \mathrm{kg}^{-1} \cdot \mathrm{min}^{-1} \text { versus } \\
\text { standard care }\left(\mathrm{O}_{2} \leqslant 2 \mathrm{~L} \cdot \mathrm{min}^{-1}\right)\end{array}$ & $\begin{array}{l}\text { HFNC }<1 \mathrm{~L} \cdot \mathrm{kg}^{-1} \cdot \mathrm{min}^{-1} \text { versus } \\
\text { standard care }\left(\mathrm{O}_{2}<2 \mathrm{~L} \cdot \mathrm{min}^{-1}\right)\end{array}$ & $\begin{array}{l}\text { HFNC } 3 \mathrm{~L} \cdot \mathrm{kg}^{-1} \cdot \mathrm{min}^{-1} \text { versus } \\
\text { standard care }\left(\mathrm{O}_{2}<2 \mathrm{~L} \cdot \mathrm{min}^{-1}\right)\end{array}$ \\
\hline \multicolumn{4}{|l|}{ Short-term outcomes } \\
\hline Escalation of care/treatment failure & $12 \%$ versus $23 \% ; p<0.001$ & $14 \%$ versus $33 \% ; p<0.002$ & $14 \%$ versus $20 \% ; p=0.21$ \\
\hline $\begin{array}{l}\text { Rescue by HFNC in standard care } \\
\text { group }\end{array}$ & $61 \%$ & $63 \%$ & No crossover allowed \\
\hline Comfort/feeding score & & Favours HFNC & \\
\hline Admission to PICU & No difference $(10.5 \%)$ & No difference ( 13\%) & No difference $(13 \%)$ \\
\hline Transfer to PICU in another hospital & No difference & & No difference \\
\hline Duration of stay in PICU & No difference & & \\
\hline Endotracheal ventilation & No difference $(\sim 1 \%)$ & & None \\
\hline Days of $\mathrm{O}_{2}$ supplementation & No difference & No difference & Favours HFNC \\
\hline Length of stay & No difference & No difference & No difference \\
\hline Conclusions & $\begin{array}{l}\text { Significantly lower rates of } \\
\text { escalation of care due to } \\
\text { treatment failure }\end{array}$ & $\begin{array}{l}\text { HFNC did not reduce time of } \\
\text { oxygen supplementation }\end{array}$ & $\begin{array}{l}\text { No difference in escalation of } \\
\text { respiratory support }\end{array}$ \\
\hline
\end{tabular}


No study showed a reduction in PICU admissions [7-9]. The average rate of PICU admission ( 12\%) was comparable in all studies, and none was powered to assess this outcome. Notably, the rate of endotracheal ventilation was $<1 \%$ in the study cohorts $[7,9]$.

Thus, it seems that the use of HFNC might have a role only as a rescue therapy in the context of standard care, or as an initial therapy if the criteria for its use are more selective. For example, all the three studies [7-9] kept the target $S_{\mathrm{pO}_{2}}$ higher than the $90 \%$ recommended by the AAP [1], and this could affect the interpretation of their results as to the role of HFNC for initial therapy. The criteria need to be defined according to the population risk factors (post prematurity, clinical background like cardiac or respiratory or neuromuscular disease), age group and severity of disease. Identifying such criteria could possibly result in avoiding PICU admission, and increase the cost-effectiveness. This is supported by a recent review that concluded that HFNC should be used as a rescue treatment for hypoxaemic infants who have not responded to standard nasal oxygen therapy [11]. RALSTON [12] analysed the benefits and harms of HFNC in infants with bronchiolitis and also suggested the need to define the appropriate population in whom to use HFNC in bronchiolitis, and to limit the use of HFNC to rescue therapy by protocolising treatment failure criteria for standard care.

Use of HFNC in a more selective population may also allow for better organisational planning in busy paediatric departments during winter time. Focusing on such a population will allow better monitoring and will improve the safety of care in general wards. It will also allow better utilisation of more expensive resources.

Overall, HFNC seems to be safe in paediatric wards. The study by DuRAND et al. [9] highlights the need for education on how to use HFNC. As opposed to NCPAP, the pressures are not measured during HFNC, and a $50 \%$ leak at the nares is recommended by the manufacturer. Occluding the nares, or the mouth, with a pacifier for example, might result in air leak [9]. Furthermore, most of the paediatric wards do not have a PICU in their centre, and caution needs to be exercised while taking care of infants with more severe disease with HFNC, which after all should be viewed as a modality of noninvasive ventilation. Thus, a more stringent and evidence-based set of criteria for HFNC implementation might lead to improved overall care, safety and potentially outcomes.

Finally, the three RCTs used different flow rates during delivery of HFNC [7-9]. DuRAND et al. [9] used a higher flow, trying to optimise the mode of respiratory support, based on physiological studies $[5,6]$. However, they did not evaluate the discomfort of the infants, that could theoretically worsen the work of breathing and mask any potential benefit of HFNC. This is consistent with a recent RCT [13], which indeed suggested that a $3 \mathrm{~L} \cdot \mathrm{kg}^{-1} \cdot \mathrm{min}^{-1}$ flow rate did not reduce the risk of treatment failure compared to the $2 \mathrm{~L} \cdot \mathrm{kg}^{-1} \cdot \mathrm{min}^{-1}$ arm in severe bronchiolitis in infants $<6$ months of age. Failure rate, and worsening respiratory distress or air leak were comparable, but discomfort was more frequent on $3 \mathrm{~L} \cdot \mathrm{kg}^{-1} \cdot \mathrm{min}^{-1}$ [13]. High flows like those used by Durand et al. [9] might increase the rate of air leak, even though the actual rate was low, did not differ statistically from the standard care, and there was no instance of serious deterioration among the subjects involved in this study. The results of these studies do not support the use of $3 \mathrm{~L} \cdot \mathrm{kg}^{-1} \cdot \mathrm{min}^{-1}[9,13]$.

In summary, the current literature does not support routine or initial use of HFNC in infants with moderate bronchiolitis in the paediatric ward unless the criteria for its use are more selective. Rescue therapy might be justified if the threshold for failure of standard care is better delineated and is used as criteria for rescue HFNC. Such a threshold could adopt a common simple denominator, possibly based on the failure criteria of published studies [12], which will allow its use in paediatric wards. Future prospective studies are warranted to close these gaps of knowledge, defining the most appropriate criteria for initial therapy and for rescue therapy.

Conflict of interest: A. Kugelman has nothing to disclose.

\section{References}

1 Ralston SL, Lieberthal AS, Meissner HC, et al. Clinical practice guideline: the diagnosis management, and prevention of bronchiolitis. Pediatrics 2014; 134: e1474-e1502.

2 Lin J, Zhang Y, Xiong L, et al. High-flow nasal cannula therapy for children with bronchiolitis: a systematic review and meta-analysis. Arch Dis Child 2019; 104: 564-576.

3 Luo J, Duke T, Chisti MJ, et al. Efficacy of high-flow nasal cannula vs standard oxygen therapy or nasal continuous positive airway pressure in children with respiratory distress: a meta-analysis. J Pediatr 2019; 215: 199-208.

4 Arora B, Mahajan P, Zidan MA, et al. Nasopharyngeal airway pressures in bronchiolitis patients treated with high-flow nasal cannula oxygen therapy. Pediatr Emerg Care 2012; 28: 1179-1184. 
5 Hough JL, Pham TMT, Schibler A. Physiologic effect of high-flow nasal cannula in infants with bronchiolitis. Pediatr Crit Care Med 2014; 15: e214-e219.

6 Milési C, Baleine J, Matecki S, et al. Is treatment with a high flow nasal cannula effective in acute viral bronchiolitis? A physiologic study. Intensive Care Med 2013; 39: 1088-1094.

7 Franklin D, Babl FE, Schlapbach LJ, et al. A randomized trial of high-flow oxygen therapy in infants with bronchiolitis. N Engl J Med 2018; 378: 1121-1131.

8 Kepreotes E, Whitehead B, Attia J, et al. High-flow warm humidified oxygen versus standard low-flow nasal cannula oxygen for moderate bronchiolitis (HFWHO RCT): an open, phase 4, randomized controlled trial. Lancet 2017; 389: 930-939.

9 Durand P, Guiddir T, Kyheng C, et al. A randomized trial of high-flow nasal cannula in infants with moderate bronchiolitis. Eur Respir J 2020; 56: 1901926.

10 de Benedictis FM. The effectiveness of high-flow oxygen therapy and the fascinating song of the Sirens. JAMA Pediatr 2019; 173: 125-126.

11 O’Brien S, Craig S, Babl FE, et al. "Rational use of high-flow therapy in infants with bronchiolitis: what do the latest trials tell us?" a Paediatric Research in Emergency Departments International Collaborative perspective. $J$ Paediatr Child Health 2019; 55: 746-752.

12 Ralston SL. High-flow nasal cannula therapy for pediatric patients with bronchiolitis: Time to Put the Horse Back in the Barn. JAMA Pediatr 2020; in press [https://doi.org/10.1001/jamapediatrics.2020.0040].

13 Milési C, Pierre AF, Deho A, et al. A multicenter randomized controlled trial of a 3-L/kg/min versus 2-L/kg/min high-flow nasal cannula flow rate in young infants with severe viral bronchiolitis (TRAMONTANE 2). Intensive Care Med 2018; 44: 1870-1878. 